\title{
MECHANISM OF F2F STUDENT SUPPORT IN OPEN AND DISTANCE LEARNING SYSTEM: Indian Experience
}

\author{
Dr. Anil K. DIMRI \\ Regional Director \\ Indira Gandhi National Open University \\ Regional Centre, Dehradun, INDIA
}

\begin{abstract}
Present paper seeks to analyse the system of face to face programme delivery adopted by Indira Gandhi National Open University(IGNOU) for its distance learners over a period of two and half decades. The paper also analysed that with the growth in student enrolment, new schemes of face to face programme delivery was developed and implemented and some of them have made significant contribution in developing a suitable network. However, the scheme originally launched on the philosophy of institutional networking, resource sharing, collaboration and convergence was highly successful and mainly responsibly for the growth of ODL in India. The schemes of learners support centres launched subsequent only supplemented the existing scheme. Attempt has also been made to critically analyse the pros and cons of each of the scheme offered for ODL learners for face to face interaction and how a particular scheme was more acceptable.
\end{abstract}

Keywords: Programme delivery, student support services, open and distance learning, learners support centres.

\section{INTRODUCTION}

Open and Distance Learning System (ODL) has gone through different phases of evolution since its inception across the world, including developing country like India, where its acceptance got momentum with the establishment of Department of Correspondence Education in Delhi University. World wide changes has also encouraged educational planners and administrators of India to further institutionalized the ODL system in the country, consequently Andhra Pradesh Open University was established in 1982. However the major breakthrough in ODL System in India has been witnessed with emergence of Indira Gandhi National Open University (IGNOU) in 1985. Over a period of time 14 Open Universities (OU) and 154 Directorate of Distance Education were established in India. It has also been noticed that with growth of ODL it was embodied with varying nomenclature including correspondence education, home study, independent study, external studies, continuing education, distance teaching, self-instruction, adult education, technology-based or mediated education, learner-centred education, open learning, open access, flexible learning and distributed learning, virtual learning and internet supported learning (COL, 2013). This change in the monoculture was mainly associated with programme delivery system adopted during the course of time. For instance correspondence education was essentially on the print material supplied to the learners by using postal services. With the passage of time not only audio-video cassettes and CDs were used to supplement the print material but the programme was also delivered through use of information and communication Technology (ICT) including radio broadcast and television. On the other hand the educational philosophy of open learning provided considerable freedom to the learners in terms of medium or media, whether print, 
on-line, television or video, place of study, whether at home, at the workplace or on campus, pace of study, whether closely paced or unstructured, support mechanisms, whether tutors on demand, audio conferences or computer-assisted learning, web supported learning and entry and exit points as per the convenient of the learners.

This flexibility of study has social relevance, economic importance and geo- physical acceptance in the developing country like India where study can easily be integrated with the work or other engagement including social responsibility and economic and noneconomic activities. Therefore, ODL mode of learning is highly suitable to the diversified socio economic, geo-physical and ethno-cultural conditions of India mainly due to its capacity not only to absorb a large segment of college entrants but also provide an opportunity of higher education ranging form in services bureaucrats, technocrats, corporate professionals to enhance their skill while working but also to housewife, road side mechanics and those engaged in farm and non farm activities and informal sectors. It also provides opportunity to passionate learners to join new programme in order to gain knowledge and those already pursuing programmes of conventional system to join add on qualification programmes from basket of variety. Thus, ODL has made significant dent in the field of higher education during the last three decades particularly with the establishment of Indira Gandhi National Open University (Dimri, 2006).

\section{STUDENT SUPPORT SERVICE IN ODL: IGNOU Model}

Although IGNOU started its journey with launch of two academic programmes in 1987 enrolling about 4300 learners, with the passage of time, there has been tremendous growth in its student enrolment, resulting in $\mathbf{0 . 6 9 7}$ million learners enrolled during 2012-13 sessions with 3.02 million on its rolls. In order to provide Student Support Services (SSS), it has envisaged a three tier system of facilitating its learners viz-a-viz national, state and grassroots' level with its headquarters at New Delhi, Regional Centres in the state capitals and even beyond state capital, depending on the area of the state and enrolment in a particular Regional Centres and geo-physical conditions of the state and the third tier which is actually the interface between the student and the university at the grass root level is the Learners Support Centres of varying nature where learners get opportunity to not only interact with the academic counselors and peers for resolving their academic queries but also get administrative and academic support. These LSCs are established across the jurisdiction of the RC in the institute of higher learning and NGOs. On the other hand the school of studies and operational Divisions, Centres and Institutes has been established it its Hqrts in New Delhi to develop course materials and provide academic and administrative support. Therefore the delivery of programme through LSCs has paramount importance considering the characteristics of ODL learners.

In the present paper an attempt has been mode to analyse the evolution system of face to face delivery mechanism of ODL with reference to IGNOU as it has major share of ODL enrolment in India. Paper also seeks to analyse how the new system of LSC has developed to augment with the with the technological advancement on the one hand and to fulfill the mandate of the university on the other, Therefore, the present paper is based on the analysis of information available in published unpublished documents of the university and the synthesis of the experience which researcher gained over a period time.

\section{EVOLUTION OF LEARNERS SUPPORT CENTRES (LSCS)}

Presently IGNOU is delivering its programme through different types of LSCs, prominent among them are Regular Study Centre (SC), Recognised Study Centres(RSC), Programme Study Centres(PSC), Partner Institute(PI), Special Study Centres(SSC), Tele Learning Centres (TLC), Study Centres under Poverty Index (North Bihar Pattern) (NBP), Special Study Centres for Economically and Educationally Backward Block(SSC EEBB). Besides these LSCs auxiliary scheme of programme delivery were also introduced from time to time and prominent among them were Sub Study Centre, Distance Learning Facilitators(DLF) Empanelled Internet Access Points (EIAP), Work Centres (WC), Skill Development Centres(SDC) and Community Information Centres (CIC). It may be noted that 2789 Learners Support Centres are in active 
operation, including 981 PSCs and 628 SCs which constitute to the total LSCs respectively.

35.17 and 22.52 percent of

\section{ROLE OF COORDINATORS AND PROGRAMME INCHARGE OF LSCS}

The functioning of study centre depends on the performance of the coordinator who has to perform multifaceted activities as indicated below:

$>$ To coordinate the work of the individual counselors and act as a liaison between the University, Regional Centre and the LSC.

$>$ To be responsible for the maintenance of all records and registers in respect of the activities of the SC either academic or administrative.

$>$ To supervise the work of the non-teaching staff members

> All the communications from the University, Regional Centre and the LSC will be addressed to the Coordinator and is authorized signatory.

$>$ To inform the students of the time and date allotted to them for attending the contact programmes, tutorials etc.

$>$ To keep LSC open on the days fixed by the University and assigned Counsellors specific days on which they have to come.

$>$ To ensure timely evaluation of written assignments and sent feedback to the learners and keep the records of the same.

$>$ To extended library support to the students visiting LSC for contact programmes and guidance

$>$ To ensure that the LSC is properly equipped with the Study material and the necessary audio and video equipment, tapes etc. for imparting teaching to the students and ensure that the audio and video equipment are kept in proper working order.

$>$ To be available at the concerned LSC between the appointed times at least three days in a week, (the days of the week will be as notified by the University). One of which will be Sunday, for answering any doubts of students and for counseling them. In case, the Coordinator is not able to attend to his duties on the notified days or has to be away from work for reasons beyond his control he shall make alternate arrangements to ensure that the work of the LSC is not affected.

> To shall abide by the instruction issued from time to time by the University and shall submit periodical reports on the progress of the courses, the students as may be required.

$>$ To ensure discipline in the LSC consistent with the aims and objectives of the University.

$>$ To perform such other duties as are assigned by the University from time to time for the effective functioning of Study Centre.

\section{REGULAR STUDY CENTRES (SC)}

The scheme of regular study centre (SC) is mainly successful in the institute of higher learning such as Government and Government Recognized UG and PG colleges and such other organizations and institutions. A formal proposal is received from the head of host institutions along with the panel of three names for appointment as Coordinator. An MOU is signed between the head of the host institution and Regional Directors. Regional Director or his representative after assessing the feasibility of establishing the Study Centres makes an onthe -spot visit and also meet the candidates recommended for the post of part time Coordinator. Regional Director then submits its evaluation report to IGNOU headquarters for final decision. If IGNOU decides to establish a Study Centre at the Host Institute, Regional Director signs the M.O.U. and returns one copy to the Head of the Host Institute. The Coordinator is appointed simultaneously and takes charge of the Study Centre and makes it operational. 


\section{Face-to-Face Program Delivery Mechanism in ODL}

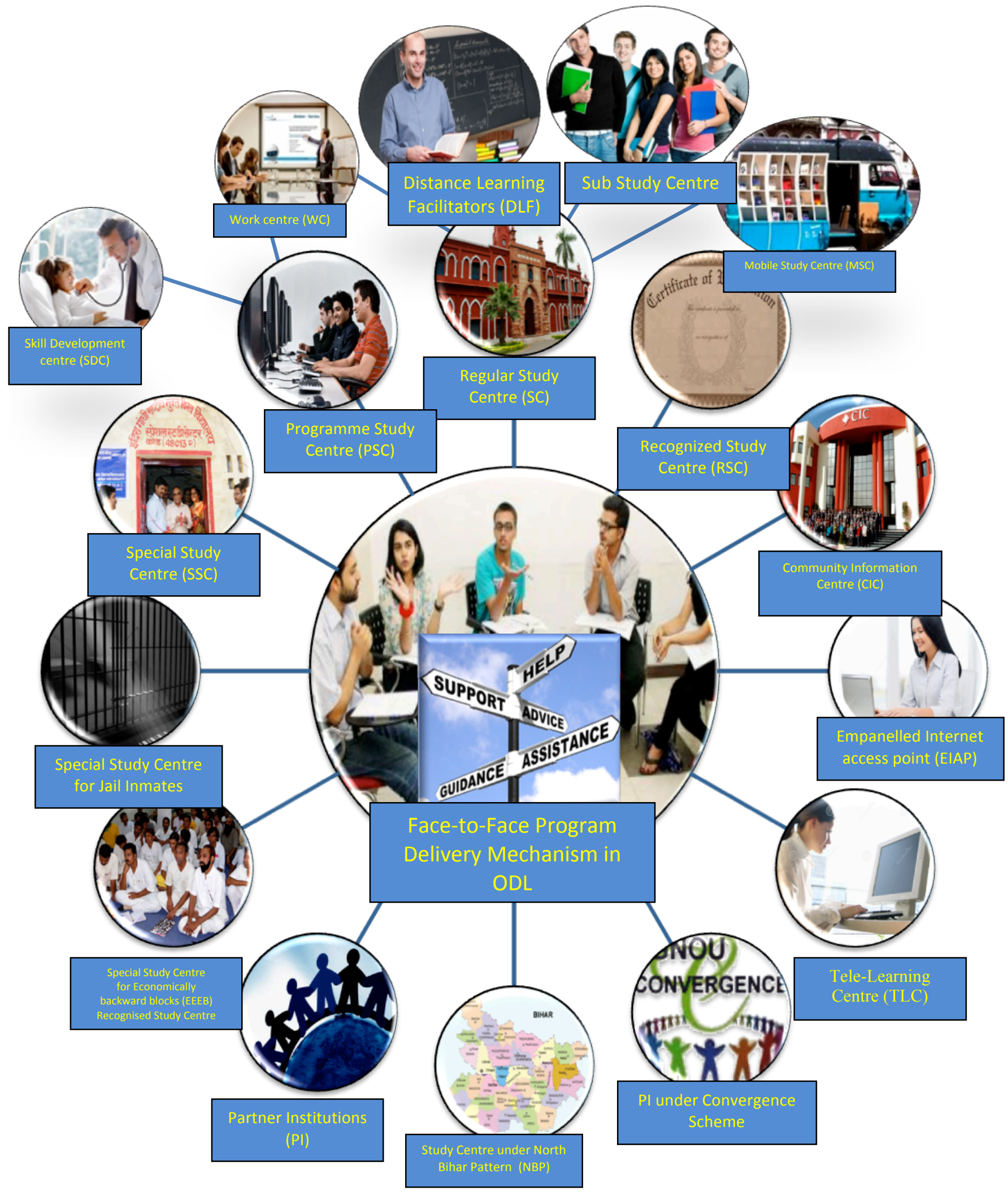


Coordinator of SC is responsible for overall academic, financial and administrative functioning of the Study Centre. The Coordinator is appointed on the recommendations of the Head of the Host Institute from among the panel of three names submitted to the University. Besides coordinators SC is also manned support staff drawn normally from the existing staff of the host institute. The number of part time functionaries can vary total enrolment, number of programmes offered at the Study Centre and also taking in to consideration the work load.

As per the requirements of the study centres coordinators and assistant coordinators are assisted and supported by the support staff who are suppose to perform the activities such as assisting the Coordinator in handling students' queries, pre-admission counseling and on-the-spot admission wherever applicable, receiving and acknowledging the assignment responses from the learners, by issuing receipts and give them to the evaluators, return the same to the learners after obtaining the comments from the evaluators and maintain the records thereof, to consolidate grades of evaluated assignments and help the Coordinator in transmitting the same to the Regional Centre within due date, to help the Coordinator in maintaining the accounts of the Study Centre, to provide necessary assistance to the Coordinator and Asst. Coordinator as per their instructions in respect of functioning of the Study Centre and to assist the Coordinator in respect of all administrative matters of the Study Centre. The University meet all the expenses to meet the activities of student support services at the SC.

Sub-Study Centre of IGNOU is an extension of the main SC to which it is attached. A SubStudy Centre is established in a place where a sizable number of students are enrolled in the vicinity but a full fledged SC is not viable. It normally provides counselling and assignments evaluation facilities to the students. A sub- study centre is managed by an Assistant Coordinator who functions under the guidance of the Coordinator of the main centre. All the administrative and financial matters of the Sub-Study Centre are handled by the main centre only. All the matters related to the Sub-Study Centre are routed through the Coordinator of the main centre.

\section{RECOGNISED STUDY CENTRES (RSC)}

It is evident to note that after the introduction of Scheme of Regular study centre, the scheme of recognized study centre was also introduced with some structural changes. For instances recognized study centre was also manned with the coordinator, nevertheless the infrastructure and other facilities were to be provided by the host institution. Financial commitment on IGNOU in meeting the recurring expenditure was minimum except meeting the honorarium of the coordinator. However, the payment for conduct of Term End Examination was borne by the University.

The arrangement of counseling was made by the host institutions and expenditure in this regard was also borne by them. These institutions were mainly established in Public Sector. Undertaking that have interest in benefiting public in general and their employee in particular. Similarly there was no restriction on implementation of the programme at this centre depending on the availability of academic counselors.

The concept of a RSC is based on sharing of the financial liability for establishing and operating the centre. Any organization or Institute which is willing and able to share the financial burden and has the necessary infrastructure can be considered for establishing recognized centre. The requirements for infrastructure are same as those for a SC. Basically the arrangement is that the sponsoring organization provides the entire basic infrastructure including furniture and equipment and also meets the recurring expenditures. University taken the responsibility of appointing coordinator from among the panel provided by the host institution andand meet all expenses for conduct of examination and evaluation of assignments. 


\section{PROGRAMME STUDY CENTRES (PSC)}

Development of academic programme is continuous process in the University system including ODL System. In the year 1990 IGNOU launched Diploma in Computers in Office Management (DCO) where requirement of practical exposure was essential. Therefore, the scheme PSC for programme delivery was introduced and subsequently BCA, MCA programmes of School of Computer and Information Sciences (SOCI) were launched and the programmes of other school of studies were also launched through this scheme. A PSC can be housed in an institute/organization, which possesses necessary infrastructure facilities and academic expertise as per the requirement for the conduct of academic support services and is willing to provide those facilities for use of IGNOU students on mutually agreed terms and conditions mainly following the principle of convergence, resource sharing and networking.

The PSC also has a part-time Programme Incharge who is responsible and accountable for all the activities of IGNOU in respect of a given programme. The PSCs have contributed significantly enrolment mainly due to flux of a large populace of learners in computer science programme particularly during 1999-2000. However, the importance of PSC was realized by the university and attempt was made to strengthen these PSC continued to capture the attention policy makers of the university as a result in the year 2012 the norms were further relaxed and programme study centres with enrolment of $\mathbf{3 0}$ students were made entitled to additional infrastructure and manpower.

The PSC also has to perform academic as well as administrative activities including organizing counseling and audio-visual sessions, arranging practical sessions, demonstration, field work etc., receiving assignments from the students, evaluating assignment by approved counselors and sending feed back to the students and grade sheets to the RC, maintain records of activities and accounts, providing regular feed back reports to the RC, provide information about IGNOU and its programmes to general public, generating bio-data of academic counselor and getting them approved. The expenditure towards academic and administrative activities is borne be the university.

Work Centres are also established for programme with practical component in the institute/organization having programme specific equipments/labs for conduct of practicals as and when required. These are generally set up only when the facilities available at PSC/SC are not sufficient to cope with the increased number of students. For this the PIC will identify the institutes and send the proposal to the respective RC. A 'Work Centre' is to be established in an institute/Organization/

industry which possesses the necessary infrastructural facilities and academic expertise for a given programme or programmes of the same discipline and is willing to make these available to IGNOU within the framework of the prescribed norms. The prospective institute/organization/industry is identified by the concerned Coordinator/Programme Incharge who forwards a detailed proposal to the RC indicating the details of infrastructural facilities available and also their acceptance of the payment structure. The proposal will be accorded approval from the Regional Centre. A 'Work Centre' functions under the administrative control of the SC/PSC to which it is attached. Funds in respect of the Work Centre are released through the SC/PSC and its account will be maintained by them. There may be more than one work centres attached to a SC/PSC and the functions of a work centre will be one or more as determined by them which mainly include conduct of practicals/field sessions and examination, assignment handling, feed back/quality control, information to students, demonstrative access to workshop/apparatus/computers/site equipment/ drawing board/technical library. Students are allocated to the Work Centre by the PIC at the PSC or Coordinator of the SC to which the Work Centre is attached. The schedule of practicals/theory counseling at the Work Centre is prepared by the PIC and intimated to the Work Centre. 
This scheme of F2F programme delivery system was launched in 1999 with the objective to establish these centres in the institution and organization which are dedicated for the cause of a given disadvantaged group, possessing necessary infrastructure facilities and expertise to serve the given group, and are willing to collaborate with IGNOU for delivery of programmes to the disadvantaged. In addition to these, SSCs are to be located in the area where a particular disadvantaged groups such as rural and remote areas, SC/ST and prisons. For this purpose collaborative arrangements are worked out with the institutions and organizations such as Non-Governmental Organisations/Voluntary Organisations, Panchayats, Cooperatives, Government Departments and Public Institutions and Prison. In order to establish SSC in particular institutions the willingness of the institutions is formally obtained. Some time RC also approach reputed organization/NGO working in the area for expansion of IGNOU reach and once the host institution as well as IGNOU authority at the Regional Centre are mutually agreed to establish a SSC necessary formalities are completed to establish the SSC

The SSC has to perform multifarious activities which included promotion and publicity of programmes among the disadvantaged groups, empanelment of Academic Counselors, organized induction meetings, counseling, practical sessions etc as per the requirement of the programme, organize Audio Video Sessions, receive assignments and get them evaluated from approved academic counselors and provide feedback to learners and send the grade list to SED and its Regional Centre, maintain records of admissions, accounts, stock of furniture and equipment and other activities of the Centre, maintenance of equipment supplied by the University in good working condition, send regular feedback reports to the Regional Centre, provide information about the programmes of IGNOU to the prospective learners, help the University conduct the term-end examinations.

\section{EMPANELLED INTERNET ACCESS POINT (EIAP)}

When the Internet become available across many cities in India, the School of Computer and Information Sciences (SOCIS) realizing the importance and potential of Internet decided to make computer science programme available online. Therefore CIC, BCA and MCA programme were also offered through online, the course material already available in print from was converted into HTML and uploaded on website and the same was also provided in CD to the learners. Since majority of the LSCs/PSCs were not having access to the internet facilities therefore select number of institutes were identified as Empanelled Internet Access Points across the country to provide internet connectivity and faculty support to the learners. However, it may be noted that internet speed was not very high during that point of time and students were facing problems in managing their programmes, therefore programmes were later on integrated with regular study centres.

\section{SPECIAL STUDY CENTRES FOR EDUCATIONALLY AND ECONOMICALLY BACKWARD BLOCKS (EEEB)}

The Government of India constituted Justice Sachar Committee for preparation of a Report on the Social, Economic and Educational Status of Muslim Community of India, and Justice Ranganath Mishra Commission for identifying criteria for socially and economically backward classes among the religious and linguistic minorities, and to suggest various welfare measures for Minorities. Among other findings of Sachar Committee on Educational Conditions of Muslims, the status of higher education was described as the disparity in Graduation level education attainment rates is widening since 1970's between Muslims and all other categories in both urban and rural areas and for both genders. Only 'one out of the 25 Under-Graduate student' and 'one out of the 50 Post-Graduate student' is a Muslim in premier colleges. The share of Muslims in all courses is low, particularly at the PG level and marginal in the science stream. While 
some progress has been made over a period of time, disparities exist and the current generation of Muslims is lagging behind in the field of education and the gap between Muslims and other SRCs increases as the level of education increases and the gaps across all levels of education between Muslims and other SRCs is higher in urban areas and for women. Muslim parents are not averse to modern or mainstream education and sending their children to the affordable Government schools. Therefore, the notion that Muslims prefer only Madarsa education is wrong. The changes in educational patterns across SRCs suggest that SCs and STs have reaped advantages of targeted government and private efforts supporting their educational progress. This reflects the importance of affirmative action.

The Sachar Committee on the basis of Census 2001 has identified 100 Muslim-dominated districts where educational opportunities are minimal. The Prime Minister's High Level Committee on Social, Economic and Educational status of Muslim community of India (Sachar Committee) was to consolidate, collate and analysis information and to identify areas of intervention by the Government to address relevant issues relating to the social, economic and educational status of the Muslim community. The Report brings out clearly the educational deprivation experienced by the Muslim community and has made specific recommendations on improving the educational status of the Muslims. Access to education is critical for benefiting from emerging opportunities that are accompanied by economic growth. From lower levels of enrolment to a sharp decline in participation in higher levels of education, the situation of Indian Muslims is indeed very depressing as compared to most other Socio-Religious Communities (SRC's) and the problem is more acute for girls/women. Majority of Muslim girls and boys fail in their matriculation examinations or drop out before that. There is a high "deficit" as far as Muslim population in the higher education. In order to make serious efforts to improve educational conditions of the minorities and to integrating the minorities with the mainstream society and their overall growth and development as education is the key to all socio-economic progress and change, Indira Gandhi National Open University in the $1^{\text {th }}$ Plan (2007-2012) has decided to provide educational opportunities to the deprived regions and sections of the society identified by the Sachar Committee by establishing at least one study centre in each Block of the 100 districts.

The study centres will offer vocational programmes in addition to the BPP, BA, B.Com programmes of IGNOU, on the basis of local requirement of the Block, which after completion may help the learners in income generation. Provision of education to Muslim girls using modern communication technologies by linking up with other open universities and Muslim educational institutions for girls will be explored. In order to popularize the programmes and to encourage the enrolment of the minorities, the below mentioned elements of relaxation will be made:

$>$ There will be no restrictions as regards the number of students at SubStudy Centres for activation of a Sub-Study Centre.

$>$ There will be no restrictions regarding number of counseling sessions and

$>$ Depending on the situation of the host institution, suitable infrastructural augmentation will be made.

Apart from BPP, BA and B.Com Programmes, the Study Centres was activated for programmes such as Certificate in Computer Literacy, Computing, Food \& Nutrition, Nutrition and Child Care, Teaching of English, Teaching of Primary School Mathematics, Maternal \& Child Health, Digital Literacy Module of Sakshat ,Awareness programme in Dairy Farming, Added Product for Fruit \& Vegetable, Mushroom Cultivation, Integrated Parental Awareness, Rural Youth Training Programme, Floriculture, Bee keeping, Water Cycle Management, Shoe Upper Cutting, Shoe Upper Stitching and Shoe Lasting \& Finishing. 
The above programmes have been identified for the first phase and more programmes would be launched depending on the progress of the pilot run. All these programmes are skill-based or vocational in nature whereby learners could get jobs/employment. Where EEBBs do not even have secondary schools, establishment of Tele-learning, EduSat Centre, Auxiliary Work Centres and Mobile Work Centres will be explored. While identifying academic programmes, to explore the possibility of activating the courses already offered by the other Open Universities or NIOs in the regional languages/Urdu. The University will bear the cost of establishment and recurring expenditure of the study centres. The institutions that would be the study centres may need to provide us rent free accommodation for establishment of the study centres and support in identifying faculty/teachers for delivering the academic/vocational programmes to the students.

\section{PARTERNER INSTITUTION (PI)}

The scheme of Partner Intuitions was introduced in the year 1996 where MBA and computer programme was launched through select Partner institution. Partner institutions were given greater autonomy including independent handling of student admission process. There was provision of Coordinator at these institutions however, the coordinator was not paid honorarium by the university. For support services fee was share between the partner institution and the university. The study material to the learners of these institutions was directly sent by the Material Production and Distribution Division. At the later stage this scheme was also extended to other programmes. IGNOU signed MOU with APTECH India in 1999 which has enrolled a large number of students of Computer Science Programme. As per MOU the institute was authorized to enroll students at Delhi, however, it has taken students from across the country violating the spirit of the MOU therefore, University discontinued the agreement by terminating the MOU with APTECH. While terminating the MOU the learners were given opportunity to opt for the IGNOU learner support centre within their reach.

\section{TELE LEARNING CENTRES (TLC)}

During 2000-2001 there was tremendous growth in student enrolment in computer science programme.IGNOU launched Advanced Diploma in Information Technology (ADIT), and Bachelor of Technology (BIT) in 1999 in collaboration with Edecxcel and the Government of India, Ministry of Information and Broadcast under Virtual Campus Initiatives (VLI). In order to provide support services to the Learners University decided to established Regional Computer Labs (RCL) initially at six Rregional Centres at these RLCs Tele Learning Centres (TLC) were established. The students of computer science programmes such as Certificate in Computing (CIC), Bachelor of Computer Application (BCA) and Master of Computer Application (MCA), BIT, ADIT were attached with the TLC and later on some more programmes were activated. These TLC were under the direct monitoring and supervision RC. The purpose of establishing TLC at RCL was to curtail huge expenditure incurred on hiring computer labs, which was otherwise being paid to private institutions as computer hiring charges. The experiment was highly successful and the same is still operational at these RCs.

\section{STUDY CENTRE UNDER NORTH BIHAR PROJECT(POVERTY INDEX CENTRE)}

Experimentation with the launch of new type of LSC continued considering the geophysical condition of the country, therefore, a scheme of Study Centre under North Bihar Pattern were introduced in the year 2003. These centres were mainly established under Darbhangha Sub Region Centre to cater the Open and Distance learning needs of people of North Bihar. Initially Bachelor Degree Programme with limited number of courses and PGDRD programme was activated at this centres. These centres were managed by the coordinator. The scheme was very successful as a result this scheme was also introduced in other part of the country. 
Later on these Centres were upgraded as Regular Study Centres taking the cut off enrolment figure of a particular centre into consideration.

\section{COMMUNITY INFORMATION CENTRES(CIC)}

Computer Literacy Programme (CLP), was initially offered by IGNOU in collaboration with the Ministry of Information and Technology, Govt. of India, and respective state Governments of North Eastern States and Sikkim, is an awareness programme of one month duration. The programme was developed to help the youth of NE for acquiring basic information and skills related to MS-Office, Internet, Web technologies and Trouble shooting. The learners were attached to IGNOU Study Centres/Tele-learning centres or the Community Information Centres (CIC) of the Ministry of Information Technology A large number of CIC were activated for this purpose in the NE States. Later on the programme was also offered by other region.

\section{ANCILLARY SCHEME OF PROGRAMME DELIVERY}

WORK CENTRES (WC): In addition to above centres, there was a provision of work centres mainly for the programmes where facilities for conduct of practical component of the programme were not available at the LSCs. For instance, for the student of computer science programmes such as CIC, BCA and MCA the work centres were established in the institute public or private who were having hardware and software facilities to run the programme. However, this scheme was restricted due to operational problem and exploitation of learners by some of private institutes. The scheme of work place/centres is still available in other programmes including B Ed programme as students have to perform school based activities in their school or the school identified by them which are there work centre.

\section{Skill Development Centres (SDC)}

The programme of School of Health Science such as PGDMCH and B Sc Nursing required extended practical exposure, therefore the students are attached with SDC and these centres were established at the Primary Health Centres etc. The activities of these SDC were monitored in order to ensure required practical exposure to them.

\section{Scheme of Distance Learning Facilitators (DLF)}

With the Growth of ODL in general and IGNOU in particular the evaluation of programme delivery mechanism continued. In the year 1997 a scheme of distance learning facilitator (DLF) was introduced which was later strengthened in 1999. The main responsibility of DLF was to enroll students and also arrange counseling session for them. The DLF was also assigned the responsibility of getting the assignment of students evaluated from the academic counselors.

Though the scheme was useful particularly to extend the support in the rural areas but it could not capture movement due to number of problems. In the absence of strong monitoring mechanism the lack of interest by the scheme was gradually diapered. This scheme has been re- launched in the year 2011 with some modifications but yet to make impression.

\section{Community Colleges}

An alternative system of delivery mechanism for F2F teaching was also I developed and launched by IGNOU in $\mathbf{2 0 0 9}$ with establishment of Community colleges across the country with the aims to empower individuals through appropriate skill development leading to gainful employment in collaboration with the local industry and community. They offer the advantage tailoring programmes to local needs and state-based requirements by using approaches that will be most acceptable to workers in the given community. The community colleges generally have a year curriculum that either leads to an Associate 
Degree for transfer to an undergraduate college or to the students direct entry into any occupation or trade. Institutions which are run of the community, by the community, and for the community offering opportunities to all sections of society particularly the marginalized and disadvantaged is the rationale for the establishment of community college. These institutions were established in an educational agency/registered society/trust or corporate body rooted in community-based activities having minimum period of five years of proven service and be located in the community it seeks to serve. Community College Board which was the executive body of the community college was constituted to look after the academic matters of the College. For smooth functioning of community colleges and to provide direction academic and examination matters two more committees were also established However, due operational difficulty and several objections on the modalities of the Community College Scheme it was discontinued in 2013.

\section{NEW INITIATIVES}

\section{Distance Learning Facilitator}

IGNOU re- introduced the scheme of DLFs with the objective to extend its reach in the area where no LSC is established with an objective to enhance student enrollment at Regular Study Centre where student enrolment is very low. Therefore the main objectives was to organize promotional meetings, door-to-door contacts and discussions with district level officials, Local Self Govt. functionaries, rural/tribal heads, NGOs etc. for better enrolment in the programmes, pre-admission guidance and counseling to the prospective learners and dissemination of important deadlines and information to augment the learners. The DLF is also expected to maintain student records, encourage students to make proper use of facilities at LSCs

Students generated by DLFs are allotted to the nearby active Study Centres only and if no Regular Study Centre is existing within a radius of $50 \mathrm{kms}$ the DLF, may organize counseling sessions on week-ends at suitable locations for the socially and economically disadvantaged groups of learners by hiring academic counselors from the nearby study centres. The performance of the DLF has to be regularly monitored, therefore a DL is expected to send monthly report. In the new scheme of DLF greater emphasis on monitoring has been given which includes regular for interaction with DLF, surprise visits and performance evaluation of DLF.

\section{MOBILE STUDY CENTRES (MSC)}

IGNOU also launch a scheme of MSC on pilot mainly to cater higher education needs of socio economically disadvantaged area with low population density, poor transport network, low per capita income and high vulnerability of community of the country. The MNC operates from the main nodal Regular Study Centre from where academic counselors are willing to camp in the villages and the coordinator of the SC has very good rapport with the participating agencies including college administration from where the academic counselors are drawn and district administration for providing rent free accommodation in the village panchayats building, government schools and any other government building. The scheme has been recently launched and its progress is yet to be seen.

\section{STUDY CENTRES FOR WOMEN IN URBAN AREAS}

In conformity with the National Policy on promoting education of women, IGNOU decided to be established study centres for women in the urban areas. Although IGNOU already has scheme of special study centre for women, however, these centres are established to provide an environment of safety, security and participation to students, parents and functionaries and these centres with the objectives for promoting programme in Gender 
and Development studies, Continuing Education and Special Education. Since this scheme is launched recently, the progresses of these centres are yet to be assessed.

It is evident to note that the University made several attempts to make paradigm shift in F2F programme delivery mechanism with the growth in enrolment, however, desired result could not be achieved. Only the scheme of PSC was successful as it was replication of SC with some modification in norms for operation of scheme. When here was advert of internet in the country some of the programmes of SOCIS was provided academic support through EIAP. In order to meet is social mandate scheme of SSC was also launched to cater the educational needs of socio- economically backward disadvantaged groups by establishing SSC for rural, remote, socially disadvantaged group, women, minority and jail inmates.

IGNOU made continuous efforts to extend its policy of reaching the unreached, therefore, scheme of DLF was launched to make dent at the cluster level. While realizing the need of quality higher education in the inaccessible areas special efforts were made by establishing Poverty Index Centre under NBP. To implement the recommendation of Sachar Committee SSC for EEBB were established for enhancing enrolment of Minorities particular Muslim. Efforts in spreading IT awareness was accomplished by developing CLP programme and launching the same through CIC. The process of evolution continued with the initiation of mobile SC, SC for urban women and restoration of the DLF scheme. Therefore all these efforts were to strengthen the SSS for the learners while having F2F interaction.

\section{CONCLUDING REMARKS}

During last 3 decades, since the inception of IGNOU in the field of ODL, a number of scheme has been launched to provide academic support to the learners at LSCs. It has also been experienced that some of schemes launched by IGNOU was not successful at the grass root level mainly due to lack of proper infrastructure to manage the scheme and some time inadequate infrastructure. Over enthusiasm while launching the scheme such as EIAP during early advent of internet could not make the scheme successful, however this scheme can be very useful in the present day scenario. The Scheme of DLF lacked proper monitoring resulting in disinterest in implementing the same by the RCs, however the same has been re launched but due to past experience the RCs are reluctant to initiate the process. It can be concluded that the efforts and innovation continued over a period of time for strengthened the programme delivery mechanism in F2F mode and efforts are likely to be constituted considering the overwhelming progress made by the University in attracting the learners.

\section{BIODATA and CONTACT ADDRESSES of the AUTHOR}

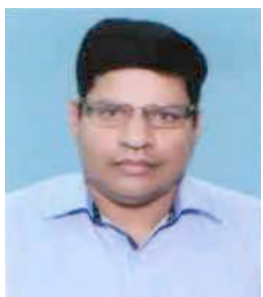

Anil K. DIMRI, holds a Ph.D. in Economics is currently working as Regional Director in Indira Gandhi National Open University (IGNOU) at its Regional Centre Dehradun. He Joined IGNOU as Assistant Regional Director at its Regional Centre-Guwahati. Prior joining IGNOU, he was Research Officer at the Centre for Micro Planning and Regional studies, Lal Bahadur Shastri National Academy of Administration Mussorie, India. He has also served as Joint Chief in the Institute of Applied Manpower Research (Planning Commission) GOI, New Delhi. He has published more than two dozen papers in national and international Journals and also submitted several research reports to different Ministries and Institutions. He was actively involved in collection of data for preparation of Human Development Index for the State of Haryana, Madhya Pradesh, Andra Pradesh and Chhatisgarh. He is also involved in imparting training in the field of Decentralized Planning, School Administration Participatory Learning and Action to the National and State level 
participants. His area of interest are Decentralized Planning and PRI Institutions, Participatory Rural Appraisal and Distance Education. He is actively involved in guiding distance learners in face to face counselling and interactive radio counselings. He also authored three books in the field of Horticulture Planning, Decentralized Development and Distance Education. He has also supervised four Ph.D. in Applied Economics. His current responsibilities education administration, student support services, supervision and maintenance of Learner Support Centres (LSCs) and academic, administrative and financial management of Regional Centre and LSCs.

Anil K. DIMRI

Assistant Regional Director, Indira Gandhi National Open University,

Regional Centre B-1/33 Sector H Aliganj, Lucknow India

Phone-91-0522-2364893, email: dimrianilk2002@Yahoo.co.in

\section{REFERENCES}

Commonwealth of Learning and Asian Development Bank (1999). An Overview of Open and Distance Learning, Trainers Toolkit 001.

Dimri,IMRI, A. K AND Amit, C. (2006). Hierarchy of e-learning delivery mechanism: A paradigm shift, Asian Association of Open University Journal, Vol. 2 No.1.

Keegan, D. (EDS), (1993), Theoretical principals of distance education, London Routledge.

Regional Services Division, IGNOU, (2013). Status Reports of Regional Centres

SHARMA, R .C. (1999). Networked distance education in India, Indian Journal of Open Learning, 8(2), 147-156.

SHARMA, C. R. (2001). On line delivery of programme: A Case study of IGNOU, International Review of Research in Open and Distance learning, 1-2. 